www.jmscr.igmpublication.org

Impact Factor 5.84

Index Copernicus Value: 71.58

ISSN (e)-2347-176x ISSN (p) 2455-0450

crossref DOI: https://dx.doi.org/10.18535/jmscr/v5i10.146

Journal Of Medical Science And Clinical Research

\title{
Incidence of Adenocarcinoma Prostate and Correlation with S.PSA and Digital Rectal Examination and Bone Scintigraphy in Our Hospital
}

\author{
Authors \\ Dr Girish H.R ${ }^{1}$, Dr Jose V. Francisco ${ }^{2}$, Dr B Revanth Kumar ${ }^{3}$ \\ Kempegowda Institute of Medical Sciences and Research Centre K.R Road, VV Puram Bangalore \\ Pin 560004 INDIA \\ Corresponding Author \\ Dr B Revanth Kumar \\ Resident in Dept of Surgery, Kempegowda Institute of Medical Sciences and Research Centre K.R Road, \\ VV Puram Bangalore Pin:560004 INDIA \\ Email: revanthb50@gmail.com, Ph:+918885114182
}

\begin{abstract}
Serum prostate specific antigen (PSA) has been used as an accurate means of detecting and monitoring prostate cancer. An analysis of PSA levels, digital rectal examination and bone scan findings was carried out in a group of patients with a view to determine whether PSA can accurately predict bone metastases in carcinoma prostate and its correlation with digital examination and bone metastasis status. In 32 case series, 30 cases on followed-up after treatment of the primary, 2 of total 32 cases received hormonal therapy. one out of three with normal PSA had bone metastases. In 25 cases with positive bone scans, 23 had elevated PSA levels (mean $79.9 \mathrm{ng} / \mathrm{ml}$ ). In an untreated patient with elevated PSA, a bone scan may be required to exclude bone metastases, whereas during follow-up after treatment, a normal PSA level may obviate a "routine" bone scan.
\end{abstract}

Keywords: Serum prostate specific antigen (PSA), adenocarcinoma prostate, bone scintigraphy, hormonal therapy, metastases.

\section{Introduction}

Serum prostate specific antigen (PSA) assay has been suggested as an accurate means of monitoring prostate cancer patients ${ }^{[1,2]}$. PSA, a glycoprotein produced by epithelial cells of both normal and cancerous prostatic tissues is valuable in assessing the disease status before treatment and during follow-up ${ }^{[2,3]}$. Studies comparing PSA levels i.e., the conventional tumour marker for carcinoma prostate, have shown better correlation of serum PSA levels and disease activity and metastasis status ${ }^{[4]}$. Serial bone scintigraphy has been accepted as a routine step in the pretreatment and follow-up identification of patients with metastases in the bone. It has been reported recently that this does not need to be performed as frequently as it is at present ${ }^{[5]}$, PSA helps in identifying the metastatic status prior to bone scintigraphy. However, there are published reports contradicting the above information. Leo et al have shown that despite clinical and scintigraphic evidence of the progression of bone metastases, 
serum PSA levels in the post orchidectomy /hormonal therapy period remained low in many patients ${ }^{[6]}$. This study was conducted in order to correlate serum PSA levels, DRE, and bone scintigraphy by injecting $15 \mathrm{mCi}$ of "Tcm-MDP intravenously in patients with biopsy proven adenocarcinoma of prostate.

\section{Materials and Methods}

Between June 2014 and August 2017, 32 consecutive patients with adenocarcinoma prostate who underwent digital rectal examination, PSA evaluation and "Tcm-MDP bone scans were selected for the study. Examination, PSA evaluation followed by transrectal prostatic biopsy and histopathological confirmation and Bone scans was followed. All bone scans were interpreted independently by one of the authors who had no knowledge of the serum PSA level at the time of scan interpretation. The scans were read as positive for metastases if two or more focal areas of increased radionuclide uptake were present. Serum PSA assays were performed using immunoradiometric assay (IRMA), which employed two monoclonal antibodies directed against two different antigenic sites on the PSA molecule. The normal range in our laboratory is 0$4 \mathrm{ng} / \mathrm{m} 1$. Study group was divided into two based on the PSA level, one between 0-4 ng $\mathrm{ml}$ and the other above a $4 \mathrm{ng} / \mathrm{ml}$. The analysis was carried out to see whether if PSA level could predict the outcome of a bone scan and clinical findings correlating to stage of bone metastases can be detected.

\section{Results}

The PSA levels and bone scan results in 32 patients are given. In 30 cases on follow-up after treatment of the primary, 6 out of 8 cases with normal PSA had a negative bone scan. In the 2 of total 32 cases received hormonal therapy, the PSA levels were generally lower than others in the study group. Two out of eight with normal PSA had bone metastases. In 25 cases with positive bone scans, 23 had elevated PSA levels (mean
$79.9 \mathrm{ng} / \mathrm{ml}$ ) and 2 out of rest cases with positive bone scan where found to have normal PSA levels indicating PSA levels sometimes misguides regarding staging of tumor. In those with normal PSA, 2 out of 3 patients had negative scans. Digital examination of all 32 cases revealed, out of 25 cases had positive bone scan of which 21 cases had mucosal fixity and hard consistency of prostate, rest 4 cases had hard consistency without mucosal fixity. Out of 7 cases which are negative for bone scans 2 cases had mucosal fixity without hard consistency and 5 cases had hard consistency of prostate with mucosal fixity. Two cases of hormonal therapy had hard consistency without mucosal fixity.

Table.1 Utility of PSA levels in predicting bone metastases

\begin{tabular}{|l|c|c|c|}
\hline $\begin{array}{l}\text { BONE } \\
\text { SCAN }\end{array}$ & $\begin{array}{c}\text { S.PSA } \\
\text { (ELEVATED) }\end{array}$ & $\begin{array}{c}\text { S.PSA } \\
\text { (NORMAL) }\end{array}$ & TOTAL \\
\hline POSITIVE & 23 & 02 & 25 \\
\hline NEGATIVE & 01 & 06 & 07 \\
\hline TOTAL & 24 & 08 & 32 \\
\hline
\end{tabular}

Table .2

\begin{tabular}{|l|c|c|c|}
\hline $\begin{array}{l}\text { DRE(in positive } \\
\text { scan) }\end{array}$ & $\begin{array}{c}\text { Elevated } \\
\text { PSA }\end{array}$ & $\begin{array}{c}\text { Normal } \\
\text { PSA }\end{array}$ & TOTAL \\
\hline HC+MF & 20 & 1 & 21 \\
\hline HC without MF & 03 & 1 & 04 \\
\hline
\end{tabular}

Table.3

\begin{tabular}{|l|c|c|c|}
\hline $\begin{array}{l}\text { DRE(in negative } \\
\text { scan) }\end{array}$ & $\begin{array}{c}\text { Elevated } \\
\text { PSA }\end{array}$ & $\begin{array}{c}\text { Normal } \\
\text { PSA }\end{array}$ & TOTAL \\
\hline HC without MF & 04 & 1 & 05 \\
\hline MF without HC & 02 & 0 & 02 \\
\hline
\end{tabular}

\section{Discussion}

Serum PSA level corresponds well with disease activity in prostatic malignancies ${ }^{[1]}$. Preoperative PSA levels are useful for the staging of disease as reported by Chybowski et $\mathrm{al}^{[7]}$. Following treatment such as orchidectomy serum PSA levels 
may drop to undetectable levels and rise with disease progression. In the present study only two patients with normal PSA levels revealed bone metastases. Bone scintigraphy has been the gold standard in detecting bone metastases. But siginificant correlation have been observed using PSA levels, DRE preoperatively helping in predicting the status of metastasis prior to bone scan. Thus the present correlation is in form of indicating the disease status and stage of disease before the metastatic workup and helping to lay down treatment guidelines and indicating the prognosis of the disease. Leo et al showed that following hormonal manipulation, $34 \%$ of patients were found to have normal PSA levels, despite documented evidence of progression of bone metastases. In the present series the PSA levels in patients who underwent orchidectomy was high as in those who had been treated hormonally.

\section{References}

1. LANGE, $\mathrm{P} \mathrm{H}$, ERCOLE, $\mathrm{C} \mathrm{J}$, LIGHTNER, D J ET AL, The value of serum prostate specific antigen determination before and after radical prostatectomy, /. Urol., 141, 873-879 (1989).

2. STAMEY, $\mathrm{T}$ A, KABALIN, J N, McNEAL, J E ET AL, Prostate specific antigen in the diagnosis and treatment of adenocarcinoma of the prostate: II. Radical prostatectomy treated patients, /. Urol., 141, 1076-1083 (1989).

3. STAMEY, T A, YANG, N, HAY, A R ET AL, Prostate-specific antigen as a serum marker for adenocarcinoma of the prostate, New Engl. J. Med., 317, 909-916 (1987).

4. FERRO, M A, BARNES, I, ROBERTS, J $\mathrm{M}$ and SMITH, $\mathrm{P} \mathrm{J}$, Tumour markers in prostatic carcinoma. A comparison of prostate specific antigen with acid phosphatase, Br. J. Urol., 60, 69-71 (1987).

5. TERRIS, $\mathrm{M}$ K, KLONECKE, A S, McDOUGALL, I R and STAMEY, T A, Utilization of bone scans in conjunction with prostate-specific antigen levels in the surveillance for recurrence of adenocarcinoma after radical prostatectomy, J. Nucl. Med., 32, 17131717 (1991).

6. LEO, M E, BILHARTZ, D L, BERGSTRALH, E J and OESTERLING, $\mathbf{J}$

$\mathrm{E}$, Prostate specific antigen in hormonally treated stage D2 prostate cancer: is it always an accurate indicator of disease status? /. Urol., 145, 802-806 (1991)

7. CHYBOWSKI, F M, KELLER, J J L, BERGSTRALH, E J and OESTERLING, J E, Predicting radionuclide bone scan findings in patients with newly diagnosed untreated prostate cancer: prostate specific antigen is superior to all other clinical parameters, /. Urol., 145, 313-318 (1991) 